\title{
Complexity of Functional Urban Spaces Evolution in Different Aspects: Based on Urban Land Use Conversion
}

\author{
Guolei Zhou $\mathbb{D}^{\text {D, }}$, Chenggu Li $\mathbb{D}$, Yanjun Liu, and Jing Zhang \\ School of Geographical Sciences, Northeast Normal University, 5268 Renmin Street, Changchun 130024, Jilin, China \\ Correspondence should be addressed to Guolei Zhou; zhoug1186@nenu.edu.cn and Chenggu Li; lcg6010@nenu.edu.cn
}

Received 15 May 2020; Accepted 27 July 2020; Published 27 September 2020

Guest Editor: Jun Yang

Copyright (C) 2020 Guolei Zhou et al. This is an open access article distributed under the Creative Commons Attribution License, which permits unrestricted use, distribution, and reproduction in any medium, provided the original work is properly cited.

\begin{abstract}
The evolution of urban spatial structure and urban land use is a topical issue in urban studies. The analysis of the complexity of functional urban spaces evolution is valuable for a deeper understanding of the changes in urban spatial structure. Taking the central city of Changchun as the study area, the paper uses the urban land conversion method to analyze the spatial and temporal characteristics of functional urban spaces evolution in different aspects. The study found that the evolution of functional urban spaces presents significant spatial and temporal differences in different stages and different aspects. There is a close relationship between functional urban spaces evolution and scale. As the scale becomes smaller, the spatial differences and patterns of functional urban spaces evolution become more complex. In the context of rapid urbanization, the mutual replacement of functional urban spaces is frequent, which is not conducive to the sustainable development of urban space as a whole. This study will deepen the understanding of the evolution of urban spatial structure and the complexity of urban systems and provide theoretical support for the optimization and sustainable development of urban spaces.
\end{abstract}

\section{Introduction}

A city is a large system composed of social, economic, ecological, resource, environmental, and other subsystems [1-3]. Urban complexity is closely related to human interests, and a deeper understanding of urban complexity will help achieve sustainable development of the city [4-6]. The fields involved in the urban system are extensive. It is challenging to comprehensively understand the urban system from a single field of study $[7,8]$. Geography, urban planning, economics, sociology, and other disciplines analyze urban complexity from different perspectives [9].

Research on the complexity of urban space has attracted the attention of scholars. Complex methods, such as urban fractal theory [10-12], cellular automata [13-16], and selforganization theory $[7,17,18]$, are used to analyze the complexity of urban land use changes or urban spatial evolution $[19,20]$. The study of urban space complexity focuses on three aspects: urban subsystems, urban system structure, and urban space structure evolution. Population, transportation, land use, and the economy are examples of urban subsystems that have received considerable academic attention [21-24]. Urban boundaries, urban landscape structures, and urban morphological structures are topical issues in the study of the complexity of urban system structures [25-27]. The mathematical model and scenario simulation of urban spatial structure evolution are the key points of urban spatial structure evolution research [28-33].

The diversity of functional urban spaces also serves as a measure of urban complexity [34]. Functional urban spaces research is a widely researched topic in the field of urban studies [22]. Comprehensive knowledge of the evolution of functional urban spaces furthers an understanding of the evolution of urban spatial structure [22]. However, most of the existing literature on functional urban spaces focuses on identifying the types of these spaces using new data or methods. New data from taxi OD trips, POI, human activity, mobile phones, social media, and vehicle trajectories are used to identify urban functions [35-42]. Previous studies have focused on the identification and classification of functional urban spaces using a variety of data and methods; however, little attention has been paid to the complexity of 
how the use of urban space has evolved. This study uses urban land use conversion to obtain the expansion and replacement of urban land. The study then analyzes the temporal and spatial characteristics of the distribution and replacement of functional urban spaces. By analyzing the relationship between functional urban spaces distribution and replacement, this paper analyzes the temporal and spatial differences of functional urban spaces evolution from four aspects: the central city, concentric zone, direction zone, and direction-ring zone. Based on this, the paper further analyzes the spatial pattern of functional urban spaces evolution and the complex evolution of these spaces at different points.

To accurately describe the spatial and temporal characteristics of the evolution of functional urban spaces, a city that is in the process of rapid development is needed as a case study. Changchun is a less developed city, and functional urban spaces are in a period of rapid expansion and replacement [22]. Our research ideas can be applied to other less developed cities in the world. We have used conventional data and methods similar to those used in existing research and have not only identified the types of functional urban spaces but also analyzed the increases and decreases of functional urban spaces. In addition, we have explored the spatial and temporal characteristics of these spaces' evolution. More importantly, we analyzed the complexity of this evolution from the perspective of different aspects and proved that as the scale shrinks, the evolutionary process of functional urban spaces becomes more complex. We believe that it is necessary and meaningful to understand the evolution of urban functions from different aspects. Study on the complexity of functional urban spaces evolution helps further an understanding of the evolution of urban spatial structure and the complexity of urban systems and provides theoretical support for the sustainable development of urban space.

\section{Study Area and Methods}

2.1. Study Area. Changchun is the capital of Jilin Province and is located in Northeast China, with an area of $20,594 \mathrm{~km}^{2}$ and a population of 7.54 million, as recorded in 2015 (Figure 1). Changchun city is composed of seven municipal districts, two county-level cities, and one county. The total area of the seven municipal districts is $7,557 \mathrm{~km}^{2}$. The study area of this paper, the central city, covers an area of $612 \mathrm{~km}^{2}$ and is the centre of the Changchun municipal districts. This paper studies the ring features, direction features, and direction-ring features of the evolution of functional urban spaces in the central city of Changchun.

The ring road is an important element in shaping the urban space. There are four ring roads in the central city of Changchun. These four ring roads divide the central city into five concentric rings. $\mathrm{R}-1$ is the zone within the first ring road, with an area of $19 \mathrm{~km}^{2}$. R-2 is the zone between the first and second ring roads, with an area of $52 \mathrm{~km}^{2}$. The zone between the second and third ring roads is R-3, with an area of $99 \mathrm{~km}^{2} . \mathrm{R}-4$ is the zone between the third and fourth ring roads, with an area of $128 \mathrm{~km}^{2}$. Lastly, R-5 is the outermost zone outside the fourth ring road, with an area of $314 \mathrm{~km}^{2}$. The average area of the five concentric rings is $122.4 \mathrm{~km}^{2}$. Using People's Square as the centre, this article divides the central city of Changchun into eight directions. Starting from the north, the area of the central city in clockwise directions is $36.3 \mathrm{~km}^{2}, 100.5 \mathrm{~km}^{2}, 59.8 \mathrm{~km}^{2}, 111.7 \mathrm{~km}^{2}$, $87.3 \mathrm{~km}^{2}, 133.0 \mathrm{~km}^{2}, 47.2 \mathrm{~km}^{2}$, and $36.2 \mathrm{~km}^{2}$. The average area of the central city in eight directions is $76.5 \mathrm{~km}^{2}$. Then, we superimposed the four ring roads and the eight directions, and the central city was divided into 40 direction-ring zones. The spatial and temporal characteristics of urban function evolution can then be analyzed from a more detailed scale. The average area of each of the 40 direction-ring zones is $15.3 \mathrm{~km}^{2}$. To facilitate the comparison of the spatial characteristics of urban function evolution, we have drawn a schematic diagram of the five concentric rings, eight direction zones, and 40 direction-ring zones in the central city of Changchun and encoded them (Figure 2).

2.2. Data Resource. The detailed urban land use maps are the main data of this study, consisting of data from 2003, 2007, 2011, and 2015. The urban land use map is the "wealth" accumulated in urban planning over the years. Based on topographic maps and remote sensing images, a rough urban land use classification map can be identified. Urban planners refer to the data of the annual land transfer of the government to check the urban land use classification map. The urban planners can then obtain a detailed urban land use map. According to POI data and several field investigations, we further checked the urban land use maps to accurately understand the spatial pattern of urban land expansion and replacement. All urban land use maps are vector data. According to national urban planning standards, urban land is divided into eight categories: residential land, public service land, commercial land, industrial land, logistics and warehouse land, road and transport facility land, municipal utility land, and green space and square land. In our study, we focus on residential land (RL), public service land (PL), commercial land (CL), and industrial land (IL). These four types of urban land we focus on account for nearly $70 \%$ of the total urban land in the central city. Since the classification of urban land is sufficiently detailed, a type of urban land corresponds to a type of functional urban space. Therefore, residential land, public service land, commercial land, and industrial land are the main types of urban land, while residential space (RS), public service space (PS), commercial space (CS), and industrial space (IS) are the main types of functional urban space. In 2003, 2007, 2011, and 2015, the area of urban land in the central city of Changchun was $237.4 \mathrm{~km}^{2}, 285.0 \mathrm{~km}^{2}, \quad 322.1 \mathrm{~km}^{2}$, and $348.6 \mathrm{~km}^{2}$, respectively (Table 1 ).

\subsection{Methods}

2.3.1. Expansion of Functional Urban Spaces. The overlay analysis method was used in this paper to study the expansion of functional urban spaces distribution. Using ArcGIS9.3 software, the urban land use maps of 2003 and 


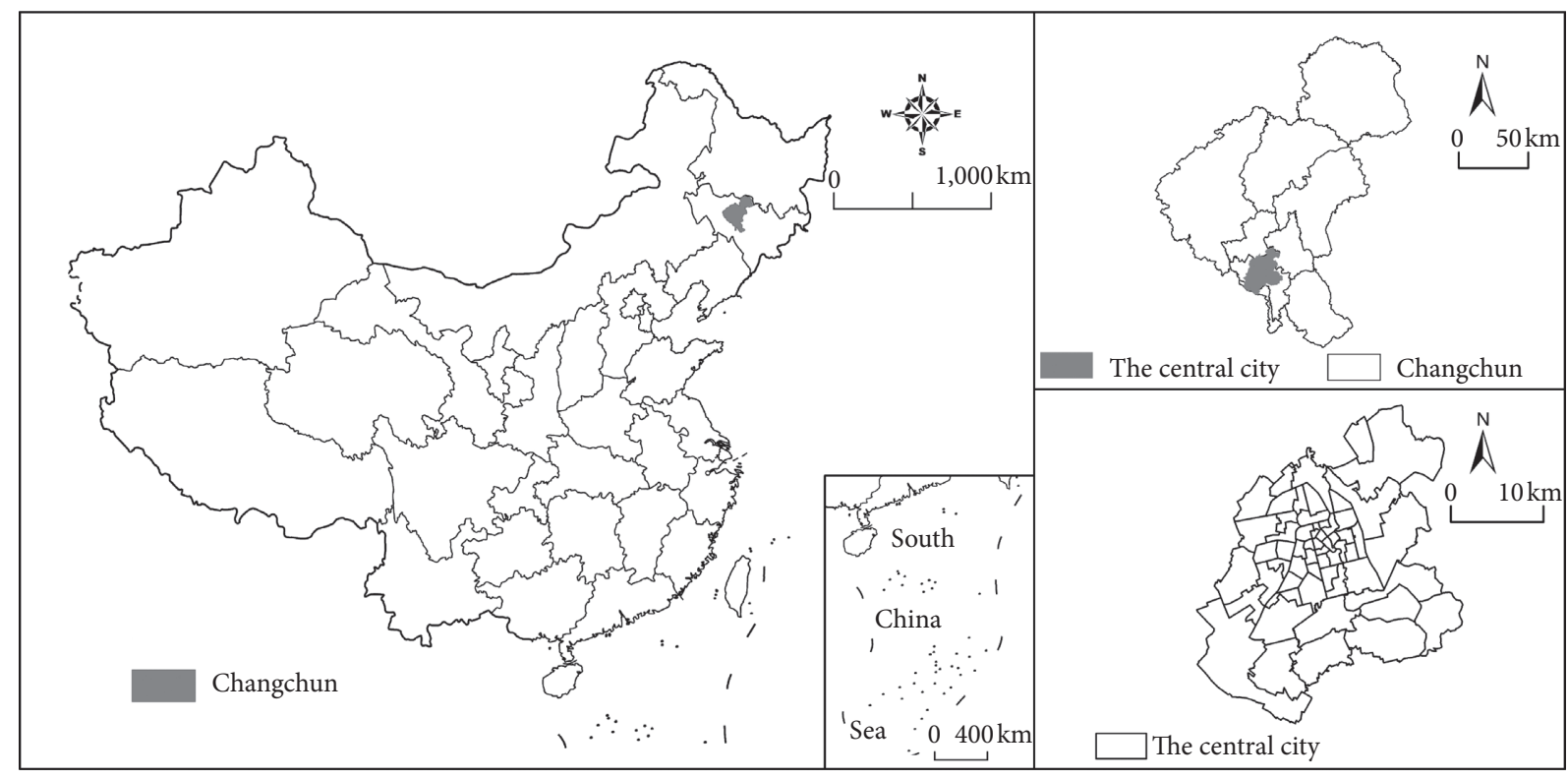

FIGURE 1: Location of Changchun.

2007, 2007 and 2011, and 2011 and 2015 were superimposed. The expansions of residential land, public service land, commercial land, and industrial land in 2003-2007, 2007-2011, and 2011-2015 were then obtained. According to the division of research units, the expansion area of different types of urban land in each concentric ring, direction zone, and direction-ring zone was calculated. Then we analyzed the ring features, direction features, and direction-ring features of residential, public service, commercial, and industrial spaces expansion. Urban land expansion refers to the increase of urban land, so the value of urban land expansion is greater than zero.

2.3.2. Replacement of Functional Urban Spaces. This article uses the transfer matrix method to analyze the replacement of urban land in the central city of Changchun. Using ArcGIS9.3 software, we used Data Management in ArcToolbox to dissolve the urban land use data for increasing the speed of calculating the transfer matrix. Then, we used the overlay analysis method and Analysis Tools in ArcToolbox to get the transfer matrix of urban land replacement and export the file in Excel format. Finally, we calculated the values of urban land replacement of each concentric ring, direction zone, and direction-ring zone. Therefore, we can obtain the relationship of replacement of different types of urban land for each research unit. The formula of the transfer matrix is as follows:

$$
A_{i j}=\left[\begin{array}{ccc}
A_{11} & \cdots & A_{1 n} \\
\vdots & \ddots & \vdots \\
A_{n 1} & \cdots & A_{n n}
\end{array}\right],
$$

where $A_{i j}$ represents the area converted from type $i$ urban land to type $j$ urban land; $n$ represents the number of urban land types. A certain type of urban land can be converted into other types of urban land, and other types of urban land can also be converted into this type of urban land. Therefore, there are three cases where the value of urban land replacement is greater than, less than, and equal to zero.

2.3.3. Spatial Pattern of Functional Urban Spaces Evolution. Using the calculation of urban land expansion and replacement, we can obtain the area of each research unit's residential, public service, commercial, and industrial land expansion, as well as the area of mutual replacement between them. First, we judged the amount of change of different types of functional urban space in each research unit by comparing the expansion area and replacement area of urban land. When urban land expansion is taking place at a faster pace than urban land replacement, it indicates that urban land expansion distribution plays a leading role. When urban land expansion is less than urban land replacement, it indicates that urban land replacement plays a leading role. When the expansion of urban land is equivalent to urban land replacement, it indicates that urban land expansion and replacement play a leading role. When urban land expansion and urban land replacement are equal to zero, it is indicated that the city is in a state of nondevelopment. Second, according to the relationship between the expansion and replacement of urban land, there are also three potential changes of urban land: decrease, increase, and unchanged. These three types of changes can occur in residential, public service, commercial, and industrial land, respectively. Based on the relationship between residential, public service, commercial, and industrial land expansion, as well as mutual replacement in each research unit, we can observe the spatial pattern of functional urban spaces evolution. In theory, there are 81 models of the four types of functional urban space evolution. However, since some models do not conform to the urban development theory, the number of actual models is far below 81. Finally, we compared the evolution of functional urban spaces in 

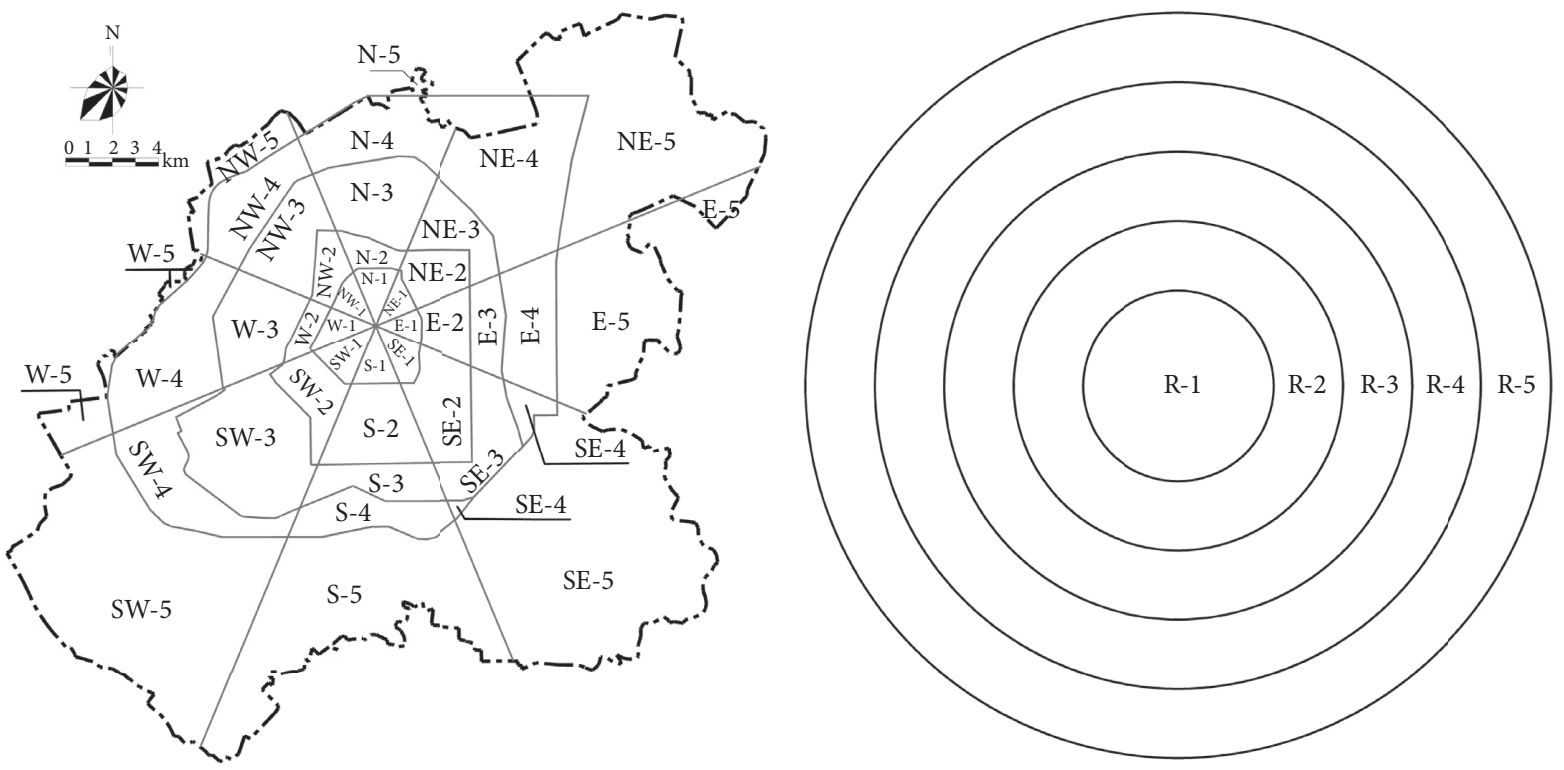

(a)

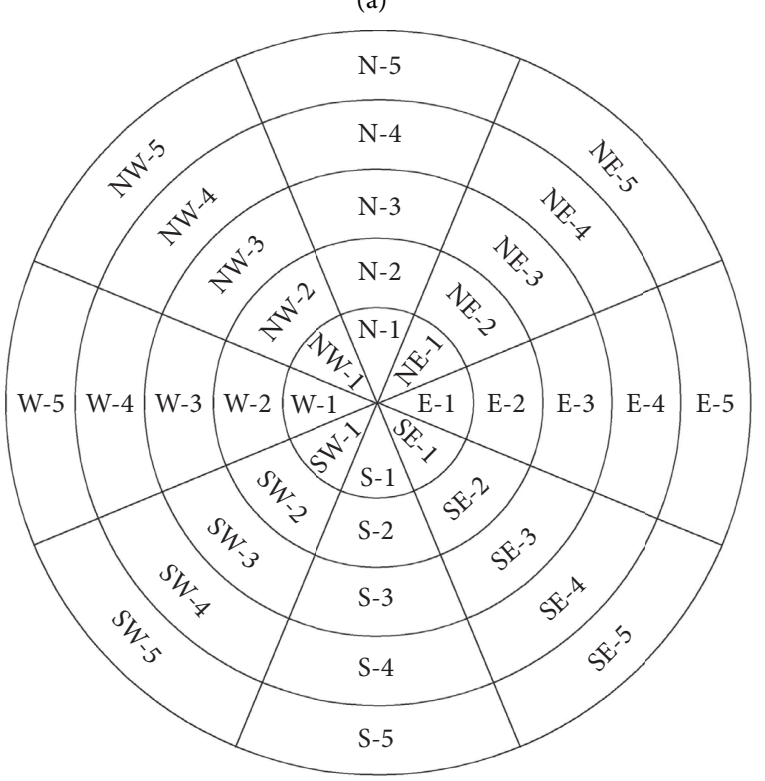

(c)

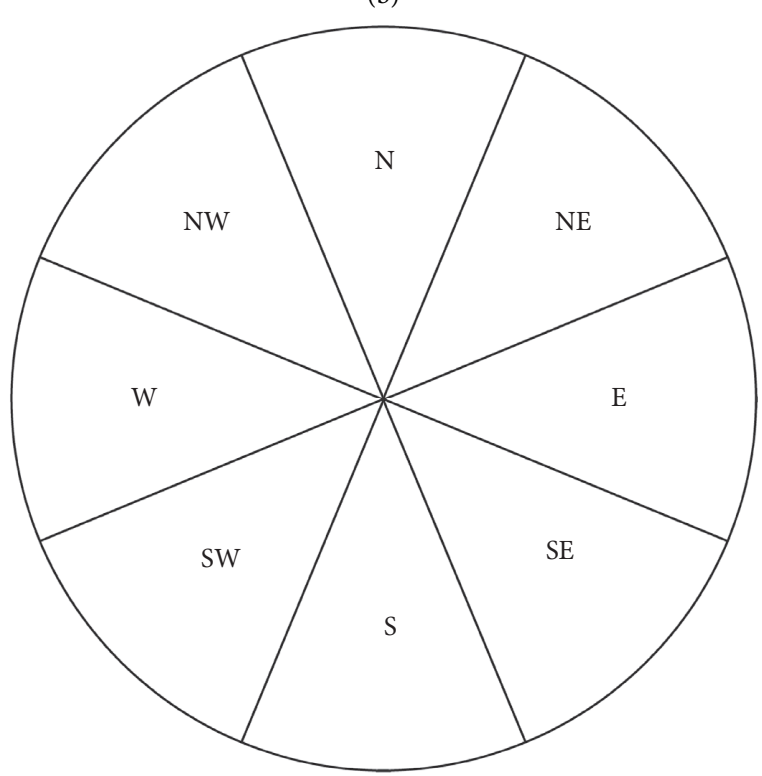

(d)

FIgURE 2: Study area and coding diagram. (a) The central city, (b) rings, (c) direction of rings, and (d) directions.

TABLE 1: Urban land use structure in the central city (2003-2015).

\begin{tabular}{|c|c|c|c|c|c|c|c|c|}
\hline \multirow{2}{*}{$\begin{array}{l}\text { Urban land use } \\
\text { types }\end{array}$} & \multicolumn{2}{|c|}{2003} & \multicolumn{2}{|c|}{2007} & \multicolumn{2}{|r|}{2011} & \multicolumn{2}{|r|}{2015} \\
\hline & Area $\left(\mathrm{km}^{2}\right)$ & $\begin{array}{c}\text { Proportion } \\
(\%)\end{array}$ & Area $\left(\mathrm{km}^{2}\right)$ & $\begin{array}{c}\text { Proportion } \\
(\%)\end{array}$ & Area $\left(\mathrm{km}^{2}\right)$ & Proportion (\%) & Area $\left(\mathrm{km}^{2}\right)$ & Proportion (\%) \\
\hline $\mathrm{RL}$ & 66.0 & 27.8 & 75.9 & 26.6 & 97.4 & 30.3 & 108.2 & 31.0 \\
\hline PL & 27.3 & 11.5 & 36.8 & 12.9 & 32.3 & 10.0 & 36.3 & 10.4 \\
\hline $\mathrm{CL}$ & 8.8 & 3.7 & 12.6 & 4.4 & 13.8 & 4.3 & 18.5 & 5.3 \\
\hline IL & 54.6 & 23.0 & 64.3 & 22.6 & 71.9 & 22.3 & 75.1 & 21.6 \\
\hline $\mathrm{RL}+\mathrm{PL}+\mathrm{CL}+\mathrm{IL}$ & 156.7 & 66.0 & 189.6 & 66.5 & 215.4 & 66.9 & 238.1 & 68.3 \\
\hline Total & 237.4 & 100 & 285.0 & 100 & 322.1 & 100 & 348.6 & 100 \\
\hline
\end{tabular}


different areas (the concentric ring zone, direction zone, and direction-ring zone) and summarized the evolutionary complexity of these spaces.

\section{Results}

3.1. General Characteristics of Urban Land Expansion and Replacement. Using ArcGIS9.3 software and the above methods, we obtained the expansion and replacement of residential, public service, commercial, and industrial land in 2003-2007, 2007-2011, and 2011-2015 (Tables 2 and 3). Through urban land expansion, the four types of urban land increased by 3462.9 ha, 3849.9 ha, and 2351 ha, respectively, in the three time periods. Through urban land replacement, the area transferred both into and out of the four types of urban land in 2003-2007, 2007-2011, and 2011-2015 was 1749.7 ha, 955.4 ha, and 461.9 ha, respectively. Functional urban spaces expansion was more active than functional urban spaces replacement from the perspective of the central city. However, different spaces exhibit different characteristics.

In the three time periods, residential land increased by $1355.8 \mathrm{ha}, 1852.0 \mathrm{ha}$, and $1478.2 \mathrm{ha}$, respectively, through urban land expansion, while industrial land increased by $1586.1 \mathrm{ha}, 1552.9 \mathrm{ha}$, and $584.8 \mathrm{ha}$ (Table 1). The expansion of residential and industrial land is notable. At the same time, the replacement of residential and industrial land is also active (Table 2). Through urban land replacement, residential land was mainly replaced by public service and commercial lands, and, simultaneously, industrial land was largely replaced by residential lands. Compared with residential and industrial land, the area of expansion and replacement of public service and commercial land was smaller. In the three time periods, the area of public service land expansion was $401.6 \mathrm{ha}, 329.0 \mathrm{ha}$, and $145.2 \mathrm{ha}$, respectively, and the area of commercial land expansion was 120.4 ha, 116.0 ha, and 142.9 ha, respectively. Public service land was mainly replaced by residential and commercial lands and also replaced a large number of residential and industrial lands. Commercial land was mainly replaced by residential and public service lands. At the same time, commercial land also replaced a large number of residential and industrial lands.

\subsection{Evolution Mode of Functional Urban Spaces in Different Concentric Circles}

3.2.1. Urban Spatial Expansion in Different Concentric Circles. The evolution of functional urban spaces in the central city of Changchun showed clear concentric features (Figure 3). Residential space increased in the three periods mentioned above. Only in the 2003-2007 period was residential space within the first ring road reduced, due to the conversion to public service and commercial space. In the first two time periods, urban land expansion led to an increase of residential land, especially outside the second ring road. In the third period, the expansion and replacement of urban land led to the increase of residential space. Urban land replacement within the third ring road had a significant
TABLE 2: Expansion area of different types of urban land in the three time periods (unit: ha).

\begin{tabular}{lccc}
\hline Urban land use types & $2003-2007$ & $2007-2011$ & $2011-2015$ \\
\hline RL & 1355.8 & 1852.0 & 1478.2 \\
PL & 401.6 & 329.0 & 145.2 \\
CL & 120.4 & 116.0 & 142.9 \\
IL & 1586.1 & 1552.9 & 584.8 \\
Total & 3463.9 & 3849.9 & 2351.1 \\
\hline
\end{tabular}

TABLE 3: Urban land transfer matrix in the three time periods (unit: ha).

\begin{tabular}{lccccc}
\hline Period & Urban land use types & RL & PL & CL & IL \\
\hline \multirow{2}{*}{$2003-2007$} & RL & - & 221.4 & 269.0 & 185.2 \\
& PL & 176.1 & - & 68.8 & 76.1 \\
& CL & 98.6 & 80.6 & - & 34.8 \\
$2007-2011$ & IL & 315.0 & 110.1 & 114.1 & - \\
\hline & RL & - & 22.6 & 44.4 & 23.9 \\
& PL & 60.2 & - & 60.9 & 19.6 \\
& CL & 52.2 & 37.0 & - & 8.0 \\
$2011-2015$ & IL & 500.8 & 73.7 & 52.1 & - \\
& RL & - & 17.2 & 14.9 & 1.4 \\
& PL & 36.6 & - & 20.7 & 0.0 \\
& CL & 26.0 & 11.7 & - & 0.0 \\
\hline
\end{tabular}

impact, and urban land expansion outside the third ring road had a similarly significant impact.

In the first two periods, public service function largely increased through urban land replacement within the second ring road and urban land expansion outside the second ring road. The situation became complicated in the 2011-2015 period. Public service space within the second ring road decreased due to urban land replacement, and urban land expansion outside the fourth ring road increased space used for public services. Between the second and third ring roads and between the third and fourth ring roads, public service space was decreased and increased, respectively, by the double impact of urban land expansion and replacement.

In all three periods, commercial space of each concentric ring had been increased. During the 2003-2007 time frame, urban land replacement within the third ring road led to the increase of commercial space, while urban land expansion outside the third ring road led to the increase of commercial space. In the second period, 2007-2011, commercial space between the first and fourth ring roads increased due to the combined impact of urban land expansion and replacement. The changes within the first ring road and outside the fourth ring road were the same as those in the first period. From 2011 to 2015, commercial land outside the third ring road increased because of the combined effect of urban land expansion and replacement. The change within the third ring road was the same as that in the period of 2003-2007.

Due to the suburbanization of industry, industrial land within the third ring road was gradually replaced by other urban lands, and industrial space continued to spread from 


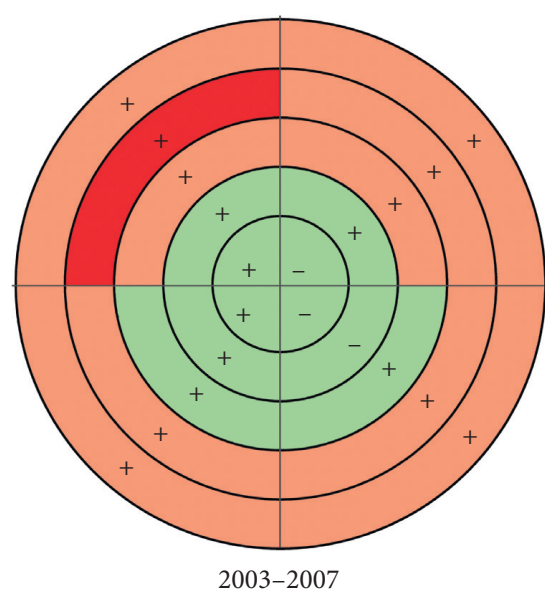

$\square$ Expansion-led
$\square$ Replacement-led

(a)
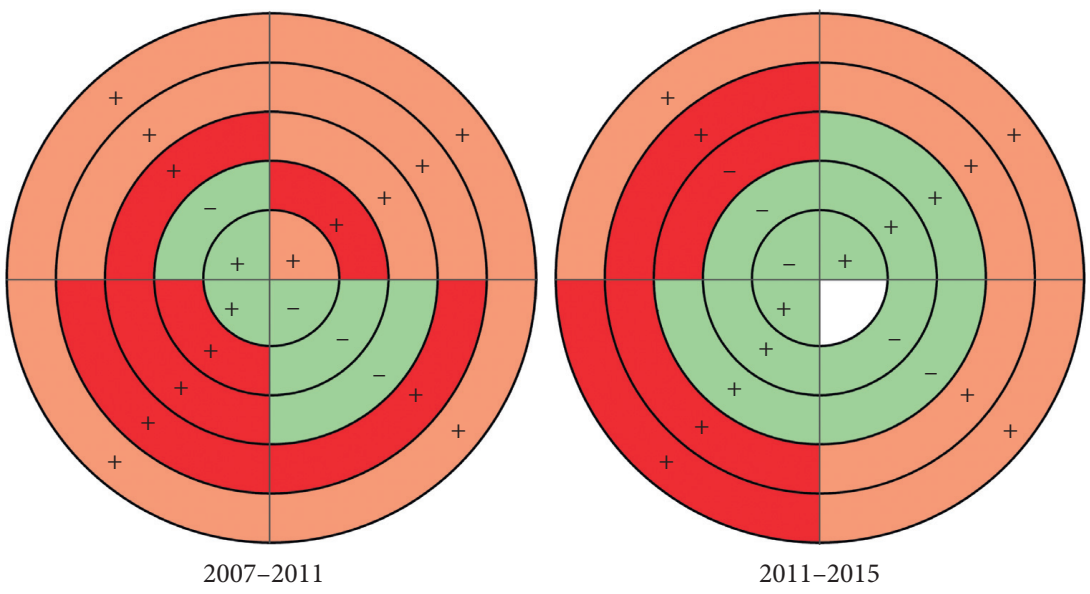

No expansion and replacement

Expansion and replacement-led

(c)

FIgURE 3: The concentric ring characteristics of functional urban spaces evolution (2003-2015). With the centre of the circle as the starting point of the coordinate system, the first, second, third, and fourth quadrants represent residential, public service, commercial, and industrial spaces, respectively. "+" indicates the increase of a certain urban space; "-" indicates the decrease of a certain urban space.

the inside ring to the outside ring. The expansion and replacement of industrial land within the first ring road disappeared from 2011 to 2015.

\subsubsection{Urban Spatial Replacement in Different Concentric} Circles. The concentric changes of urban spaces showed obvious phase characteristics (Figure 3). In zone R-1, urban land replacement was very active from 2003 to 2015. During the period of 2003-2007, residential space decreased due to the conversion into public service and commercial spaces; public service and commercial spaces increased due to the replacement of other urban spaces; and industrial space continuously decreased by the replacement of other urban spaces.

Similar to zone R-1, the four types of functional urban space in zone R-2 were also dominated by replacement, except for residential and commercial spaces in the period of 2007-2011. Residential, public service, and commercial spaces increased because of the continuous replacement of industrial and other urban spaces in the 2003-2007 time period. Residential and commercial spaces both replaced other urban spaces and continued to spread, so they increased in 2007-2011. The evolution of the four types of functional urban space in zone R-2 in the third stage was similar to evolution in the first stage. The difference was that public service space decreased by being replaced by commercial and residential spaces.

In zone R-3, the expansion and replacement of functional urban spaces were frequent in the three time periods. In the period of 2003-2007, residential and public service spaces increased due to urban land expansion. Additionally, commercial and industrial spaces increased due to the replacement of other urban spaces. In the period of 2007-2011, public service and business spaces increased by the dual role of urban land expansion and replacement. In the third period, residential and commercial spaces increased by replacing other urban spaces; public service space decreased due to the dual role of urban land expansion and replacement.

In zone R-4, the dual role of urban land expansion and replacement affected the changes of public service space, commercial and industrial spaces, and commercial and public service spaces, respectively, in the three time periods. The rest were mainly urban land expansion.

In addition to commercial space, the other three functional urban spaces in the three time periods increased by urban land expansion in zone R-5. In the three periods, the four types of functional urban space in zone R-5 increased due to urban land expansion, and commercial space was also affected by urban land replacement.

3.2.3. Mode of Functional Urban Spaces Evolution in Different Concentric Circles. According to the concentric analysis of the expansion and replacement of the four types of functional urban space mentioned in Sections 3.2.1 and 3.2.2, there are five modes of functional urban spaces evolution, three for each time period due to repetition. The mode of "increase of all functional urban spaces" occurred in zones R-3, R-4, and R-5 in 2003-2007 and 2007-2011 and occurred in zones R-4 and R-5 in 2011-2015. The mode of "decrease of CS \& IS + increase of RS \& CS" occurred in zone R-2 in 2007-2011 and occurred in zones R-2 and R-3 in 2011-2015. The mode of "decrease of IS + increase of RS, PS, \& CS" occurred in zone R-2 in 2003-2007 and occurred in zone R-1 in 2007-2011. The modes of "decrease of RS \& IS + increase of PS \& CS" and "decrease of PS + increase of RS \& CS + stability of IS" occurred in zone R-1 in 2003-2007 and 2011-2015, respectively. In general, urban land 
replacement is mainly within the third ring road, and urban land expansion occurs mainly outside the third ring road. Within the third ring road, the mode of functional urban spaces evolution reflects significant stage and regional differences.

\subsection{Evolution Mode of Functional Urban Spaces in Different Directions}

3.3.1. Urban Spatial Expansion in Different Directions. The direction features of the evolution of the four types of functional urban space were very obvious from 2003 to 2015 (Figure 4). Residential space increased in all eight directions in the three separate time periods, mainly due to urban land expansion.

Changes in public service land were more complicated. From 2003 to 2007, public service space only decreased in the south due to urban land replacement, while in other directions it increased due to the expansion or replacement of urban land. In the period of 2007-2011, public service space only decreased in the north due to urban land replacement, increased in five directions due to urban land expansion, and increased in the remaining two directions due to urban land replacement. From 2011 to 2015, public service space increased in the east by the expansion and replacement of urban land. Due to urban land replacement, public service space decreased in the west and southwest and increased in the south. In the other four directions, public service space increased due to urban land expansion.

Similar to the changes in land used for residential purposes, commercial space of the three phases increased in almost all directions due to the expansion or replacement of urban land, only in the east of the second phase due to the dual role of expansion and replacement. Commercial space only decreased in the northeast during the period of 2007-2011 and similarly in the north during the period of 2011-2015 due to urban land replacement.

In the first stage, industrial space increased in all directions except for the north due to the expansion or replacement of urban land or the dual role of expansion and replacement. In the north, industrial space decreased due to urban land replacement. In the next two periods, industrial space decreased in four and five directions, respectively, due to urban land replacement and increased in other directions, mainly due to urban land expansion.

\subsubsection{Urban Spatial Replacement in Different Directions.} The evolution of functional urban spaces in various directions presented different characteristics from 2003 to 2015 (Figure 4). Compared with the concentric characteristics of functional urban spaces evolution, the direction characteristics were more complex. In the north, urban land expansion led to an increase in residential space; the change of public service space was affected by the expansion or replacement of urban land or the dual role of expansion and replacement; the change of commercial space was affected by the expansion or replacement of urban land; industrial space decreased because of urban land replacement from 2003 to 2015.

In the northeast, in addition to commercial space, the remaining three types of functional urban space increased in the three stages. The replacement of low-grade commercial land led to a decrease of commercial space in the period of 2007-2011. Residential space increased by urban land expansion, public service space increased by expansion or replacement of urban land, and industrial space increased by urban land expansion or dual effects of expansion and replacement.

In the east, residential, public service, and commercial spaces increased in the three periods due to urban land expansion, replacement, or dual roles of expansion and replacement, while industrial space was initially increased by urban land expansion and then suffered a decrease from the dual roles of expansion and replacement.

In the southeast, an increase in residential and public service spaces during the three time periods was brought about by urban land expansion. The increase of commercial space was due to urban land replacement first and then due to urban land expansion. Industrial land use increased due to urban land expansion in the first stage and then decreased because of urban land replacement in the second and third periods.

In the south, residential space increased because of urban land expansion in the three periods, public service space decreased by replacement in the first stage and increased by expansion in the latter two time periods, and commercial space increased by expansion or replacement. Furthermore, industrial space decreased due to the dual role of expansion and replacement in the first period and then decreased by replacement in the latter two periods.

In the southwest and west, except for the decrease of public service space in the period of 2011-2015 due to urban land replacement, the four types of functional urban space in the remaining periods increased by the expansion or replacement of urban land.

In the northwest, residential, public service, and commercial spaces grew more significantly due to urban land expansion or replacement in the three periods, and industrial space expanded in the first period and decreased in the latter two periods due to urban land replacement.

3.3.3. Mode of Functional Urban Spaces Evolution in Different Directions. Just like the evolution of functional urban spaces in different concentric circles, there are also five modes of functional urban spaces evolution occurring in different directions. Due to repetition, there are three modes in the first time period and four modes in the last two time periods. The mode of "increase of all functional urban spaces" occurred in five directions (E, SE, SW, W, and NW) during the period of 2003-2007. This mode also occurred in two (SW and W) and one (NE) directions during the second and third time periods, respectively. The mode of "decrease of IS + increase of RS, PS, \& CS" occurred in two (N and NE) directions during the period of 2003-2007 and occurred in the same four directions (E, SE, S, and NW) in the periods of 

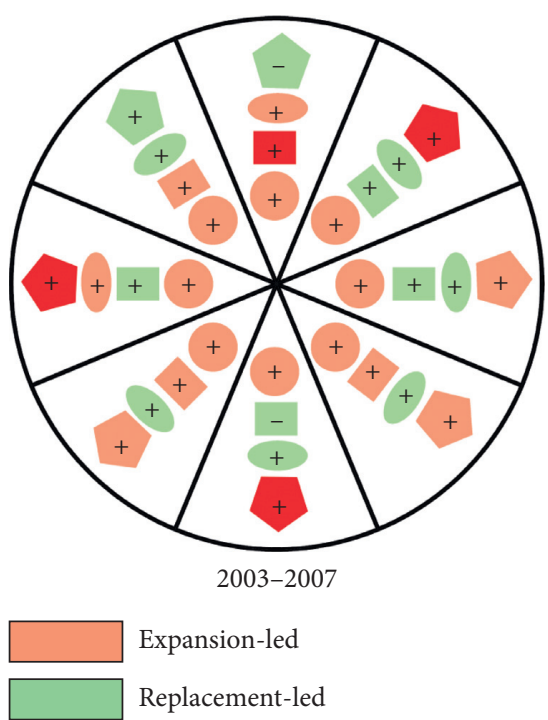

(a)

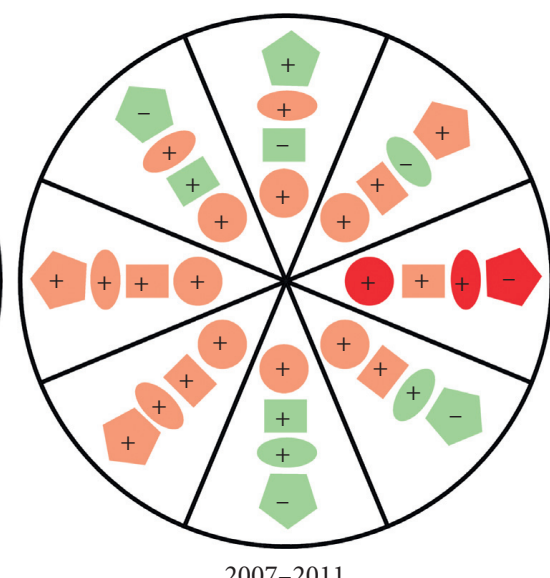

2007-2011

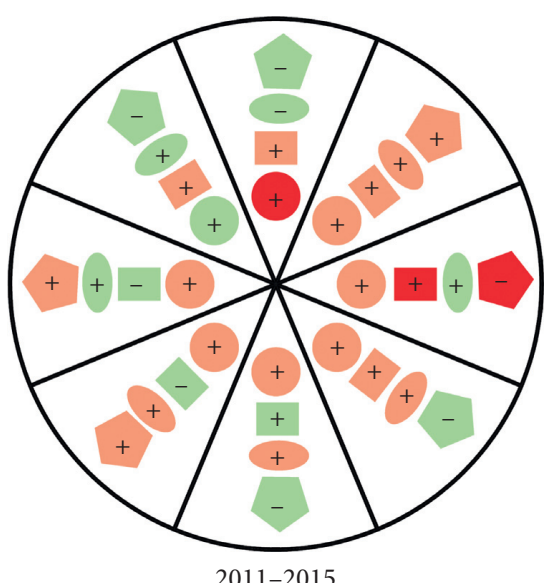

No expansion and replacement

Expansion and replacement-led

(c)

Figure 4: The direction characteristics of functional urban spaces evolution (2003-2015). Circles, rectangles, ellipses, and pentagons represent residential, public service, commercial, and industrial spaces, respectively. "+" indicates the increase of a certain urban space; "-" indicates the decrease of a certain urban space.

2007-2011 and 2011-2015. The mode of "decrease of PS + increase of RS, CS, \& IS" appeared in one direction in the first two stages ( $\mathrm{S}$ in 2003-2007 and $\mathrm{N}$ in 2007-2011) and in two directions (SW and $\mathrm{W}$ ) in the last stage. The mode of "decrease of CS + increase of RS, PS, \& IS" occurred in the northeast from 2007 to 2011, while the mode of "decrease of CS \& IS + increase of RS \& PS" occurred in the north from 2011 to 2015.

3.4. Evolution Mode of Functional Urban Spaces in Different Direction-Ring Zones. Through the analysis of concentric ring and direction features of functional urban spaces evolution, it was found that the spatial difference of functional urban spaces evolution is significant. Based on the above analysis, we further explored the direction-ring characteristics of functional urban spaces evolution and summarized the main modes of this evolution. The types of functional urban spaces evolution modes increased from 14 in the period of 2003-2007 to 20 in the 2007-2011 time frame and then moved down to 19 in the period of 2011-2015. The increase in the number of modes indicates that the interaction of urban functions tends to be more complex, and the spatial difference of functional urban spaces evolution is becoming more obvious. According to the number of research units involved in each type of functional urban spaces evolution mode, the period of 2003-2007 contained six major modes, and each of the periods of 2007-2011 and 2011-2015 contained five modes. Since other modes only occur in one or two direction-ring zones, they are not the main evolution modes. Therefore, these modes will be excluded from the discussion. Three modes exist in all three periods (Figure 5), so we need to discuss ten patterns.
Mode 1: increase of the four types of functional urban spaces guided by expansion

In this mode, the role of urban land expansion is clear. Residential, public service, commercial, and industrial spaces continuously increased due to urban land expansion from 2003 to 2015. Mode 1 involved nine research units in the period of 2003-2007 (NE-3, NE-4, NE-5, E-5, SE-5, SW-3, SW-5, NW-3, and NW-4), three research units in the period of 2007-2011 (E-5, SW-4, and SW-5), and four research units in the period of 2011-2015 (NE-5, SE-5, SW-5, and NW-3). These units were mainly distributed outside the third ring road and the southwest, northeast, and northwest.

Mode 2: decrease of PS \& IS and increase of RS \& CS guided by replacement

The suburbanization of industry and the relocation of universities led to the replacement of industrial and public service spaces by residential and commercial land use. Mode 2 involved four research units in the period of 2003-2007 (N-2, N-3, SE-2, and NW-1), six research units in the 2007-2011 time frame (N-3, NE-3, SE-2, S-2, SW-3, and W-2), and five research units in the period of 2011-2015 (SE-2, SE-3, SW-2, SW-3, and $\mathrm{W}-3$ ), which were mainly distributed between the first and third ring roads. The distribution of research units involved in Mode 2 was scattered.

Mode 3: decrease of IS and increase of RS, PS, \& CS guided by replacement

Mode 3 is the phenomenon of "suppressing the second industry and developing the third industry" often mentioned in urban studies in China. Mode 3 involved four research units in the period of 2003-2007 (E-3, SE$3, \mathrm{~S}-4$, and $\mathrm{W}-3$ ), six research units in the period of 


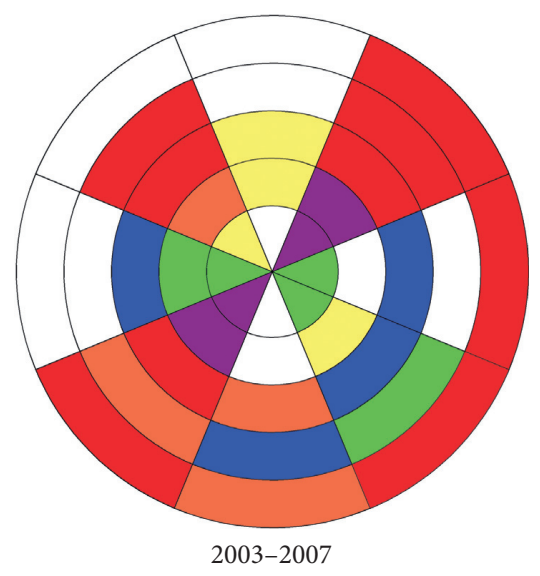

Increase of all functional urban spaces Decrease of PS and IS + increase of RS and CS Decrease of IS + increase of RS, PS and CS Decrease of RS and IS + increase of PS and CS Decrease of RS + increase of PS, CS and IS Decrease of PS + increase of RS, CS and IS

(a)
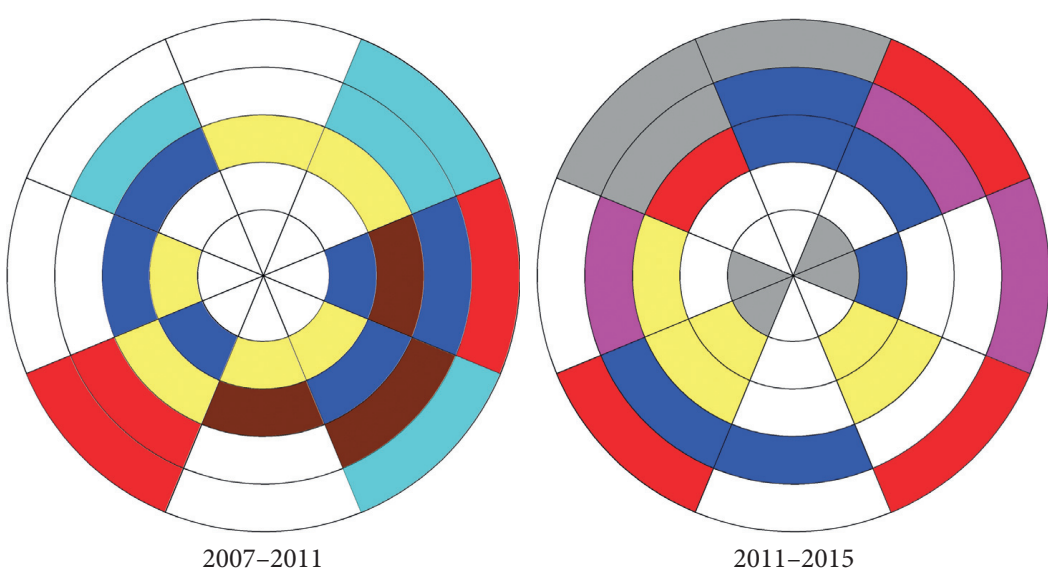

2011-2015

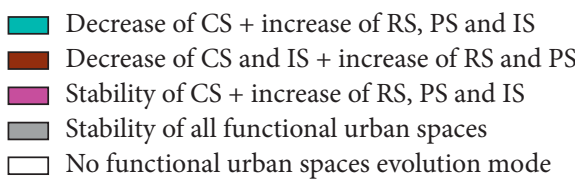

(b)

Figure 5: The mode of functional urban spaces evolution (2003-2015).

2007-2011 (E-2, E-4, SE-3, SW-2, W-3, and NW-3), and six research units in the period of 2011-2015 (N-3, $\mathrm{N}-4$, NE-3, E-2, S-4, and SW-4). These units were mainly distributed between the second and fourth ring roads and gradually transferred outward. The research units involved in Mode 3 were distributed in all eight directions in the process of "deindustrialization." Industrial land was constantly being replaced by residential, public service, and commercial land.

Mode 4: decrease of RS \& IS and increase of PS \& CS guided by replacement

Mode 4 involves five research units (E-1, SE-1, SE-4, $\mathrm{W}-1$, and $\mathrm{W}-2$ ) and only appeared in period of the 2003-2007. The research units involved in Mode 4 were mainly distributed within the first ring road and the southeast and west. The functional urban spaces of these research units were undergoing a significant phase of replacement. Other functional urban spaces were gradually replacing industrial land use. At the same time, due to the flawed urban service functions, public service and commercial spaces were continuously increased and they replaced some residential space.

Mode 5: decrease of RS and increase of PS, CS, \& IS guided by replacement and expansion

Mode 5 involves four research units (NE-1, NE-2, SW1 , and SW-2) and only appeared in the period of 2003-2007. The research units involved in Mode 5 were mainly distributed within the second ring road and the southwest and northeast. These research units are located in the inner circle of the central city, and as such functional urban space replacement prompted residential space subsidized public service and commercial spaces to improve the functions of the city. At the same time, because these research units were in the main direction of industrial development, industrial land was slightly expanded.

Mode 6: decrease of PS and increase of RS, CS, \& IS guided by replacement and expansion

Mode 6 involves four research units (S-3, S-5, SW-4, and NW-2) and only appeared in the period of 2003-2007. The distribution of the mode was relatively scattered, located in four concentric circles and three directions. The diminishment of public service space was mainly due to the replacement of administrative offices and educational land. The expansion of residential and commercial spaces was primarily due to the expansion or replacement of urban land or dual role. Lastly, the increase of industrial space was mainly because the research units involved were located in industrial concentration areas.

Mode 7: decrease of CS and increase in RS, PS, \& IS guided by replacement and expansion

Mode 7 only appeared in the 2007-2011 time frame, involved four research units (NE-4, NE-5, SE-5, and $\mathrm{W}-4$ ), and was mainly distributed outside the third ring road. The decrease of commercial space was mainly due to the replacement of low-level farmers' markets and small commodity markets by residential and public service spaces. During this period, industrial growth mainly occurred outside the third ring road. The expansion of residential land led to the increase of residential space. The relocation of educational land and the construction of exhibition facilities were the main reasons for the increase of land for public service use. Mode 8: decrease of CS \& IS and increase of RS \& PS guided by replacement and expansion 
Mode 8 only appeared in the period of 2007-2011, involves three research units (E-3, SE-4, and S-3), and was mainly distributed between the second and fourth ring roads. Residential and public service land expanded mainly between the second and third ring roads, guiding the expansion of residential and public service spaces. Industry showed a clear "deindustrialization" trend. The decrease in commercial space was largely due to low-grade commercial facilities being annexed by surrounding residential land.

Mode 9: stability of CS and increase of RS, PS, \& IS guided by distribution

Mode 9 only appeared in the period of 2011-2015, involved three research units (NE-4, E-5, and W-4), and was mainly distributed outside the third ring road. Due to the expansion of urban land, residential, public services, and industrial spaces increased. However, commercial space lagged behind, indicating that no development was taking place. Commercial land remained intact, without expansion or replacement.

Mode 10: stability of the four types of functional urban space

Mode 10 involves seven research units (N-5, NE-1, E-1, SW-1, W-1, NW-4, and NW-5) and only appeared in the period of 2011-2015. The mode was mainly distributed within the first ring road and outside the fourth ring road. Within the first ring road, the stability of the four types of functional urban spaces indicated that the urban functions had gradually stabilized through urban land replacement. Additionally, residential, commercial, and public service spaces had gradually improved, and the process of "deindustrialization" had slowly been completed. The north and northwest are not the main directions of urban space development in Changchun. This has resulted in the stagnation of urban construction in the northwest outside the third ring road and in the north outside the fourth ring road, showing evidence of "nondevelopment."

\section{Discussion}

Based on the in-depth analysis of urban land use conversion, this study analyzes the spatial and temporal characteristics of the evolution of residential, public service, commercial, and industrial spaces. The analysis used three zones: concentric ring zone, direction zone, and direction-concentric-ring zone. First, according to the distribution of the ring roads, the central city was divided into five concentric rings. We analyzed the concentric characteristics of the expansion and replacement of residential, public service, commercial, and industrial spaces. Then, taking People's Square as the centre, the central city is divided into eight directions. We analyzed the direction features of the expansion and replacement of residential, public service, commercial, and industrial spaces. Finally, combining the five concentric rings and eight directions, the central city was divided into 40 direction-ring zones. According to the expansion and mutual replacement relationship of functional urban spaces, the pattern of these spaces' evolution was summarized. Our analysis proves that the method of urban land conversion is effective, and the analysis of different scales reflects the complexity of functional urban spaces evolution.

Overall, the expansion of functional urban spaces is more active than the replacement of these spaces from the perspective of the central city. The expansion and replacement of residential and industrial spaces are more active than those of public service and commercial spaces. Residential land use is mainly replaced by public service and commercial use, and residential space largely replaces industrial land use. Residential and commercial spaces mostly replace public service space, and, lastly, commercial space is mainly replaced by residential and public service spaces.

The evolution of functional urban spaces shows prominent concentric characteristics and directional characteristics. Urban space replacement mainly occurs within the third ring road, while urban space expansion primarily occurs outside the third ring road. Between the second and fourth ring roads, expansion and replacement jointly influence the evolution of functional urban spaces. In all directions, these spaces are dominated by expansion or replacement. It is relatively rare for expansion and replacement to jointly guide the evolution of these urban spaces. The concentric and directional characteristics of different functional urban spaces evolution are different.

Based on the perspective of expansion and replacement, combined with the mutual replacement of urban space, this article summarizes the mode of functional urban spaces evolution. The types of functional urban space evolution modes increased from 14 in the period of 2003-2007 to 20 in the period of 2007-2011 and moved down to 19 in the period of 2011-2015. The period of 2003-2007 contained six major urban evolution modes, and each of the periods of 2007-2011 and 2011-2015 contained five modes. Three of these modes exist in all three periods. Therefore, there were ten main modes of functional urban spaces evolution from 2003 to 2015. It is clearly seen that, from the central city to the direction-ring zone, the scale becomes smaller, and the evolution of these urban spaces becomes more complex.

Compared with the existing literature, although our work is still a conventional study of urban space, we use a new perspective to reflect the complexity of urban space evolution through a scale comparison. Using new perspectives to study typical urban problems is a method often used by scholars. The study of urban functions has always attracted the attention of academia. Most scholars are committed to using new data or methods to identify the types of urban function [31-38], but they have not continued to use the research results for functional urban spaces evolution research. We have not only adopted a new perspective but also investigated the scale differences and complexity of functional urban spaces evolution. Our method can also be applied to other cities, especially less developed cities whose urban space is in a period of rapid development. 


\section{Conclusions}

A city is a large, complex system. This article attempts to explore the complexity of functional urban spaces evolution from different zones. Our research proves that studying the evolution of functional urban spaces from different scales is of significant value, and the research methods are feasible. Through the above analysis, we have arrived at the following conclusions:

(1) The evolution of functional urban spaces shows obvious concentric and direction features. The spatial and temporal characteristics of the evolution of different functional urban spaces are different. The evolution of functional urban spaces has different characteristics in different stages. The types of functional urban spaces evolution patterns are becoming more numerous, and the spatial differences in functional urban spaces evolution are becoming increasingly significant.

(2) Scale has a great influence on the study of functional urban spaces evolution. It is necessary to study the evolution of urban land use at different levels. As the available space shrinks, the evolution of functional urban spaces becomes more complicated.

(3) Our study has found that not only is industrial space being replaced, but so are residential, public service, and commercial spaces. In the context of rapid urbanization, the evolution of urban space is more complex. Therefore, studying the mutual replacement of different types of functional urban spaces is helpful to understand the inherent characteristics of urban spatial evolution.

(4) Lack of foresight in urban planning leads to the mutual replacement of functional urban spaces, increases the cost of urban development, and is not conducive to the sustainable development of urban space. Our research will further promote the study of the complexity of urban internal spaces. The study of urban land use evolution at different scales will enrich the perspective of urban spatial research, deepen the understanding of the evolution of urban spatial structure, and promote the updating of urban theories. Fully understanding the scale difference of functional urban spaces evolution will help us to more fully understand the inner process and characteristics of urban space evolution and provide theoretical support for the optimization of urban space in practice. Although this article explored the complexity of functional urban spaces evolution significantly, it only considers four types of functional urban spaces. In future work, we will increase the types of functional urban spaces and further explore the complexity of the evolution of urban spaces.

\section{Data Availability}

The data used to support the findings of this study are available from the corresponding author upon request.

\section{Conflicts of Interest}

The authors declare that they have no conflicts of interest.

\section{Acknowledgments}

This research was supported by the National Natural Science Foundation of China (41871158 and 41771172), Fundamental Research Funds for the Central Universities (2412018QD017), China Postdoctoral Science Foundation (2018M641760), and Education Department of Jilin Province (JJKH20201173KJ).

\section{References}

[1] Y. Chen and D. Zhang, "Evaluation of city sustainability using multi-criteria decision-making considering interaction among criteria in Liaoning province China," Sustainable Cities and Society, vol. 59, Article ID 102211, 2020.

[2] L. Zhang, J. Lu, B. B. Fu, and S. B. Li, "A review and prospect for the complexity and resilience of urban public transit network based on complex network theory," Complexity, vol. 2018, Article ID 2156309, 36 pages, 2018.

[3] A. Guo, J. Yang, X. Xiao, J. Xia, C. Jin, and X. Li, "Influences of urban spatial form on urban heat island effects at the community level in China," Sustainable Cities and Society, vol. 53, Article ID 101972, 2020.

[4] J. Yang, Y. Wang, X. Xiao, C. Jin, J. Xia, and X. Li, "Spatial differentiation of urban wind and thermal environment in different grid sizes," Urban Climate, vol. 28, pp. 1-13, 2019.

[5] L. Jiang, B. Xue, Z. Ma, L. Yu, B. Huang, and X. Chen, "A lifecycle based co-benefits analysis of biomass pellet production in China," Renewable Energy, vol. 154, pp. 445-452, 2020.

[6] X. Chen, L. Wei, and H. Zhang, "Spatial and temporal pattern of urban smart development in China and its driving mechanism," Chinese Geographical Science, vol. 28, no. 4, pp. 584-599, 2018.

[7] S. Moroni, W. Rauws, and S. Cozzolino, "Forms of self-organization: urban complexity and planning implications," Environment and Planning B: Urban Analytics and City Science, vol. 47, no. 2, pp. 220-234, 2020.

[8] L. Salvati and M. Carlucci, "Shaping dimensions of uyrban complexity: the role of economic structure and socio-demographic local contexts," Social Indicators Research, vol. 147, no. 1, pp. 263-285, 2020.

[9] S. K. Lai, "Plan-based decision making for urban complexity," Journal of Urban Management, vol. 5, no. 1, pp. 1-2, 2016.

[10] M. Bosch, R. Jaligot, and J. Chenal, "Spatiotemporal patterns of urbanization in three Swiss urban agglomerations: insights from landscape metrics, growth modes and fractal analysis," Landscape Ecology, vol. 35, no. 4, pp. 879-891, 2020.

[11] C. Tannier and I. Thomas, "Defining and characterizing urban boundaries: a fractal analysis of theoretical cities and Belgian cities," Computers, Environment and Urban Systems, vol. 41, pp. 234-248, 2013.

[12] D. Ma, R. Guo, Y. Zheng, Z. Zhao, F. He, and W. Zhu, "Understanding Chinese urban form: the universal fractal pattern of street networks over 298 cities," ISPRS International Journal of Geo-Information, vol. 9, no. 4, p. 192, 2020.

[13] R. White and G. Engelen, "Cellular automata and fractal urban form: a cellular modelling approach to the evolution of urban land-use patterns," Environment \& Planning A, vol. 25, no. 8, pp. 1175-1199, 1993. 
[14] Y. Cao, X. Zhang, Y. Fu, Z. Lu, and X. Shen, "Urban spatial growth modeling using logistic regression and cellular automata: a case study of Hangzhou," Ecological Indicators, vol. 113, Article ID 106200, 2020.

[15] C. Gao, Y. Feng, X. Tong, Z. Lei, S. Chen, and S. Zhai, "Modeling urban growth using spatially heterogeneous cellular automata models: comparison of spatial lag, spatial error and GWR," Computers, Environment and Urban Systems, vol. 81, p. 101459, 2020.

[16] S. Chen, Y. Feng, X. Tong et al., "Modeling ESV losses caused by urban expansion using cellular automata and geographically weighted regression," Science of the Total Environment, vol. 712, Article ID 136509, 2020.

[17] B. Boonstra and L. Boelens, "Self-organization in urban development: towards a new perspective on spatial planning," Urban Research and Practice, vol. 4, no. 2, pp. 99-122, 2011.

[18] E. De Bruijn and L. Gerrits, "Epistemic communities in urban self-organization: a systematic review and assessment," Journal of Planning Literature, vol. 33, no. 3, pp. 310-328, 2018.

[19] $\mathrm{Y} . \mathrm{Hu}$ and $\mathrm{Y} . \mathrm{Hu}$, "Land cover changes and their driving mechanisms in central Asia from 2001 to 2017 supported by google earth engine," Remote Sensing, vol. 11, no. 5, p. 554, 2019.

[20] O. Alipbeki, C. Alipbekova, A. Sterenharz et al., "A spatiotemporal assessment of land use and land cover changes in peri-urban areas: a case study of arshaly district, Kazakhstan," Sustainability, vol. 12, no. 4, pp. 1-15, 2020.

[21] L. Salvati, "Population distribution and urban growth in southern Italy, 1871-2011: emergent polycentrism or pathdependent monocentricity?" Urban Geography, vol. 35, no. 3, pp. 440-453, 2014.

[22] G. Zhou, C. Li, M. Li, J. Zhang, and Y. Liu, "Agglomeration and diffusion of urban functions: an approach based on urban land use conversion," Habitat International, vol. 56, pp. 2030, 2016.

[23] Z. Ma, C. Li, and J. Zhang, "Transportation and land use change: comparison of intracity transport routes in Changchun, China," Journal of Urban Planning \& Development, vol. 144, no. 3, Article ID 05018015, 2018.

[24] L. Stevens and R. G. Shearmur, "The end of location theory? some implications of micro-work, work trajectories and gigwork for conceptualizing the urban space economy," Geoforum, vol. 111, pp. 155-164, 2020.

[25] X. Liu, X. Ning, H. Wang, C. Wang, H. Zhang, and J. Meng, "A rapid and automated urban boundary extraction method based on nighttime light data in China," Remote Sensing, vol. 11, no. 9, p. 1126, 2019.

[26] K. Górny and A. Górna, "After decolonization: changes in the urban landscape of platô in praia, cape verde," Journal of Urban History, vol. 45, no. 6, pp. 1103-1130, 2019.

[27] Y. Long and Y. Ye, "Measuring human-scale urban form and its performance," Landscape and Urban Planning, vol. 191, Article ID 103612, 2019.

[28] C. Yamuand and P. Frankhauser, "Spatial accessibility to amenities, natural areas and urban green spaces: using a multiscale, multifractal simulation model for managing urban sprawl," Environment \& Planning B: Planning \& Design, vol. 41, no. 6, pp. 1054-1078, 2015.

[29] H. Du, Y. Cai, F. Zhou, H. Jian, W. Jiang, and Y. Xu, "Urban blue-green space planning based on thermal environment simulation: a case study of shanghai, China," Ecological Indicators, vol. 106, Article ID 105501, 2019.
[30] R. Ding, "The complex network theory-based urban land-use and transport interaction studies," Complexity, vol. 2019, Article ID 4180890, 14 pages, 2019.

[31] A. Guo, Y. Zhang, and Q. Hao, "Monitoring and simulation of dynamic spatiotemporal land use/cover changes," Complexity, vol. 2020, Article ID 3547323, 12 pages, 2020.

[32] J. Liu, H. Cheng, D. Jiang, and L. Huang, "Impact of climaterelated changes to the timing of autumn foliage colouration on tourism in Japan," Tourism Management, vol. 70, pp. 262-272, 2019.

[33] J. Yang, X. Luo, C. Jin, X. Xiao, and J. Xia, "Spatiotemporal patterns of vegetation phenology along the urban-rural gradient in coastal Dalian, China," Urban Forestry and Urban Greening, vol. 54, Article ID 126784, 2020.

[34] M. Carlucci, I. Zambon, and L. Salvati, "Diversification in urban functions as a measure of metropolitan complexity," Environment and Planning B: Urban Analytics and City Science, vol. 47, no. 7, pp. 1289-1305, 2020.

[35] Z. Zhou, J. Yu, Z. Guo, and Y. Liu, "Visual exploration of urban functions via spatio-temporal taxi od data," Journal of Visual Languages and Computing, vol. 48, pp. 169-177, 2018.

[36] S. Gao, K. Janowicz, and H. Couclelis, "Extracting urban functional regions from points of interest and human activities on location-based social networks," Transactions in GIS, vol. 21, no. 3, pp. 446-467, 2017.

[37] W. Tu, J. Cao, Y. Yue et al., "Coupling mobile phone and social media data: a new approach to understanding urban functions and diurnal patterns," International Journal of Geographical Information Science, vol. 31, no. 12, pp. 2331-2358, 2017.

[38] Q. Gao, J. Fu, Y. Yu, and X. Tang, "Identification of urban regions' functions in Chengdu, China, based on vehicle trajectory data," PLoS One, vol. 14, no. 4, Article ID e0215656, 2019.

[39] X. Zhang, S. Du, and Q. Wang, "Hierarchical semantic cognition for urban functional zones with vhr satellite images and poi data," ISPRS Journal of Photogrammetry and Remote Sensing, vol. 132, pp. 170-184, 2017.

[40] Y. Wang, Y. Gu, M. Dou, and M. Qiao, "Using spatial semantics and interactions to identify urban functional regions," ISPRS International Journal of Geo-Information, vol. 7, no. 4, p. 130, 2018.

[41] H. Xing and Y. Meng, "Integrating landscape metrics and socioeconomic features for urban functional region classification," Computers, Environment and Urban Systems, vol. 72, pp. 134-145, 2018.

[42] D. Yi, J. Yang, J. Liu, Y. Liu, and J. Zhang, "Quantitative identification of urban functions with fishers' exact test and poi data applied in classifying urban districts: a case study within the sixth ring road in Beijing," International Journal of Geo-Information, vol. 8, no. 12, p. 555, 2019. 